\title{
Blended learning in practice: guest editorial
}

\author{
Simon K. S. Cheung ${ }^{1} \cdot$ Fu Lee Wang ${ }^{1}$
}

Published online: 23 May 2019

○) Springer Science+Business Media, LLC, part of Springer Nature 2019

Blended learning is lexically defined as "a way of learning that combines traditional classroom lessons with lessons that use computer technology and may be given over the internet" (Cambridge 2013). The term "blended learning" is well found in the literature, and a search in Google Scholar yields over 100,000 results (Google 2019). The first appearance of the term "blended learning" dated back to 1999, while a formal definition was derived in 2003 to 2006 (Guzer and Caner 2013). Blended learning was widely defined as to combine face-to-face instruction with computermediated instruction (Osguthorpe and Graham 2003; Graham 2006). It was also regarded as a thoughtful integration of classroom face-to-face learning experiences with online learning experiences that has the proven potential to enhance both the effectiveness and efficiency of meaningful learning experience (Garrison and Kanuka 2004).

Over the past decade, enabled by many technological innovations, the teaching and learning process has undergone a lot of revolutionary changes, not only on instructional design and delivery but also on student advising and assessment. Blended learning has become an integration of traditional learning with innovative means, including but not limited to online learning, in order to create a new learning environment that improves learning effectiveness and enrich learning experience. Since 2008, the International Conference on Blended Learning (ICBL) and its predecessor, International Conference on Hybrid learning (ICHL), has been held annually to provide a platform for knowledge exchange and experience sharing among researchers and practitioners in the field. This Special Issue is a collection of selected papers from ICBL 2018 held in Osaka, Japan on 31 July to 2 August 2018 to disseminate findings and results on these new and innovative practice.

As early as 2004, blended learning was proven to have potentials to enhance both the effectiveness and efficiency of meaningful learning experience in higher education (Garrison and Kanuka 2004). Also pointed out by Garrison and Kanuka (2004),

Simon K. S. Cheung

kscheung@ ouhk.edu.hk

Fu Lee Wang

pwang@ouhk.edu.hk

1 The Open University of Hong Kong, 30 Good Shepherd Street, Homantin, Kowloon,

Hong Kong 
the implementation of blended learning could be complex for the challenge of virtually unlimited design possibilities and applicability to so many contexts. The papers in this Special Issue report different facets of blended learning practice, from the deployment of blended learning for language and health studies, implementation and application of flipped classroom, to learning engagement and collaboration in a blended learning environment. We are honored to serve as the guest editors of this Special Issue, and believe that the articles that comprise this Special Issue would provide useful reference in deploying blended learning for higher education. Here below is a brief introduction of the articles.

The first four articles describe the blended learning practice for language and nursing studies in higher education. Hirata and Hirata shared the experience of developing a web-based English language learning platform, called Sketch Engine for Language Learning (SkELL), especially for Japanese university students with lower English proficiency. The pedagogical implications of the use of SkELL as an educational tool used in the traditional language classroom were discussed. The second article by Simonova also described the deployment of blended learning for English language but in another country, Czech Republic. It aimed to discover whether blended learning could enhance the process of knowledge acquisition in language learning for two sets of students, one studying technical subjects and the other studying foreign languages. Despite differences in the results between the two groups of students, it was concluded that blended learning worked efficiently in teaching and learning English grammar for Czech students.

The third article investigated on the personalized word learning, where a profile-based method was proposed by Xie et al. for learning English as a second language. Various methods were studied in order to establish learner profiles and identify the optimal method. A learner profile model was proposed, and proven to have distinctive advantages over other baseline methods in facilitating vocabulary acquisition. The next article by $\mathrm{Li}$ et al. reported an evaluation of the deployment of mobile learning for clinical practicum in nursing education at a university in Hong Kong, based on an established framework for rational analysis of mobile education. Through a questionnaire survey and some focus group interviews, positive feedbacks were received, such as the students' satisfaction of mobile learning and the effectiveness in tracking learning progress. A factor analysis was conducted, and some different underlying factors were identified.

The following four articles describe the use of flipped classrooms for teaching and learning in higher education. Shibukawa and Taguchi shared a case study on flipped classrooms in a physiology class at a university in Japan. It aimed to identify the type of instruction that could effectively guide students to do pre-class preparation. A survey and an interview were conducted to the students to examine the effectiveness of instructions for preparation and the effectiveness of sharing learning objectives to measure students' metacognition. Based on the results, some suggestions were made for the design of a flipped class model. The next article by Tsai et al. described an interactive student response system for flipped classroom learning. The system supported flipped-classroom learning activities in the traditional classrooms, with an aim to promote more interactions in classroom learning. The evaluation showed improvement, not only on students' interaction but also on 
students' learning interest, learning attitude and learning satisfaction. The proposed system also helped teachers quickly obtain students' learning situation in classroom, and make necessary adjustment on instructional approaches or contents.

The seventh article described the use of an extended flipped classroom model in an undergraduate psychology course in a university in China. Guo proposed a flipped classroom model, called O-PIRTAS standing for objective, preparation, instructional video, review, test, activity, and summary respectively, with an aim to promote learning effectiveness. Positive evaluation results were obtained, not only on the perception of the teaching quality and peer interaction engagement but also on the generic skill development and examination performance. The next article by Jong discussed the concerns about the use of flipped classroom from the Social Science faculty members at another university in Hong Kong. It reported a quantitative study in which an established "Stages of Concern" model was used to probe in the concerns of Social Science faculty members about introducing flipped classroom into their teaching activities. While it was found that the faculty members had strong categorical concerns of "information" and "management", the findings essentially highlighted the importance on designing more precise interventions for addressing the faculty members' actual needs in deploying flipped classroom.

The last two articles change the focus to learning engagement and learning collaboration in a blended learning environment. Hui et al. conducted two studies, one on theories of interest and the other on self-determination, to an engineering course under a blended learning environment to verify the criticalness of the instructional design and learning behavior. Accordingly, a model is proposed with the addition of learning behavior and learning outcome, to connect instructional design to learning attitudes, learning behavior and learning outcome. The last article by MacLeod et al. presented a systematic literature review on student-to-student connectedness in higher education. Based on a synthesis of relevant peer-reviewed journal articles which empirically investigated the connectedness within face-to-face environment, online environment, and hybrid environment, the review identified the trends and gaps in the literature on student-to-student connectedness, and provided direction on future research studies in this topic.

The articles share some latest blended learning practice from different parts of the world. It is hoped that the findings and results can provide useful reference for researchers and practitioners in the field.

Acknowledgements The guest editors would like to thank M.J. Bishop and Stephanie L. Moore, the former and present Editor-in-Chiefs of the Journal of Computing in Higher Education, and Lakshmi Pattabhiraman and Velmurugan Inbasigamoni from the journal editorial office, for their great support to this Special Issue. Thanks also go to many anonymous reviewers for their efforts on paper review.

\section{References}

Cambridge. (2013). Cambridge advanced learner's dictionary (4th ed.). Cambridge: Cambridge University Press. 
Garrison, D. R., \& Kanuka, H. (2004). Blended learning: Uncovering its transformative potential in higher education. Internet and Higher Education, 7, 95-105.

Google (2019). Website of Google scholar. Retrieved May 15, 2019 from https://scholar.google.com.

Graham, C. R. (2006). Blended learning systems: Definitions, current trends and future directions. In C. J. Bonk \& C. R. Graham (Eds.), The handbook of blended learning: Global perspectives, local designs (pp. 3-21). San Francisco: Pfeiffer.

Guzer, B., \& Caner, H. (2013). The past, present and future of blended learning: An in-depth analysis of literature. Procedia-Social and Behavioral Sciences, 116, 4596-4603.

Osguthorpe, R. E., \& Graham, C. R. (2003). Blended learning environments: Definitions and directions. The Quarterly Review of Distance Education, 4(3), 227-233.

Publisher's Note Springer Nature remains neutral with regard to jurisdictional claims in published maps and institutional affiliations.

Simon K. S. Cheung, Ph.D. is the Director of Information Technology at the Open University of Hong Kong. He was the Director of IT Services at SPACE, University of Hong Kong, and the Associate Head of Registry and IT Services at SCE, Hong Kong Baptist University. He received his Ph.D. from the City University of Hong Kong. His publications include 24 authored or edited books, and 150 refereed journal articles, book chapters and conference papers, mainly in two distinct areas, software and system engineering, and technology in education. He received the Outstanding Publication Award from the Open University of Hong Kong in 2016.

Fu Lee Wang, Ph.D. is the Dean of the School of Science and Technology at the Open University of Hong Kong, and was the Vice President (Research and Technology) at the Caritas Institute of Higher Education and faculty member at the City University of Hong Kong. He received his Ph.D. from the Chinese University of Hong Kong. He has over 250 publications in international journals and conferences and led more than 20 competitive grants with a total greater than HK\$20 million. He is a Fellow of BCS, past Chair of ACM Hong Kong Chapter and IEEE Hong Kong Section Computer Chapter. 